\title{
Nanodiagnosis for Diagnosing COVID-19: a Brief Review
}

\author{
Beuy Joob $^{1, *(\mathbb{D})}$, Viroj Wiwanitkit ${ }^{2}$ (D) \\ Private Academic Consultant, Bangkok Thailand; beuyjoob@hotmmail.com (J.B.); \\ 2 Department of Community Medicine, Dr. DY Patil University, Pune, India 2; wviroj@ yahoo.com (V.W.); \\ * Correspondence: beuyjoob@hotmail.com;
}

Scopus Author ID 53663749900

Received: 26.07.2020; Revised: 14.08.2020; Accepted: 16.08.2020; Published: 19.08.2020

\begin{abstract}
Nanotechnology is useful for many applications. The use of nanomaterials can help create new innovations that can be applied in several aspects, including medical aspects. In medicine, nanomedicine is the specific branch of nanoscience. Applied nanomedicine is useful for diagnosis, treatment, and prevention of medical disorders. The applied nanomedicine for diagnosis, nanodiagnosis, is confirmed for its advantage. In the present day, COVID-19 is a newly emerging infectious disease that already causes pandemic worldwide. This new emerging respiratory viral infection caused the pandemic and affected more than 17 million of the world population and result in many deaths. The diagnosis of this new disease is a big challenge in medicine. Of several new attempts in diagnosis, nanotechnology is presently applied for diagnostic purposes in managing COVID-19. The applied nanodiagnosis for managing COVID-19 is an interest application of nanotechnology. In this short review, the authors discuss the applied nanodiagnosis for COVID-19.
\end{abstract}

Keywords: nanodiagnosis; COVID-19; diagnosis; pandemic.

(C) 2020 by the authors. This article is an open-access article distributed under the terms and conditions of the Creative Commons Attribution (CC BY) license (https://creativecommons.org/licenses/by/4.0/).

\section{Introduction}

Nanotechnology is useful for many applications. In medicine, nanomedicine is the specific branch of nanoscience. Applied nanomedicine is useful for diagnosis, treatment, and prevention of medical disorders. The applied nanomedicine for diagnosis, nanodiagnosis, is confirmed for its advantage. In the present day, COVID-19 is a newly emerging infectious disease that already causes pandemic worldwide [1-3]. The applied nanodiagnosis for managing COVID-19 is an interest application of nanotechnology [4]. In this short review, the authors discuss the applied nanodiagnosis for COVID-19.

\section{How can applied nanotechnology be useful for diagnostic medicine?}

In medicine, diagnosis is an important process. The diagnosis is the basic requirement that can give the information for the practitioner for proper management of the medical problem. Diagnostic medicine focuses on a good accurate and reliable diagnostic test. To produce a new diagnostic tool, advanced technology is applied. Of several new technologies, nanotechnology is already applied in producing the new medical diagnostic system.

Further development of the new nanodiagnostic tool is based on the basic nanomaterials. The nanomaterial-based tool usually has high sensitivity and can give a rapid, simple diagnosis at a low cost [5]. At present, there are many newly introduced new nanodiagnostic tools. 
The new nanodiagnostic tool for infection is interesting [6]. Since the infectious disease is a common group of medical problem, the new good diagnostic tool is necessary.

Torres-Sangiao et al. noted that nanomedicine was useful for developing an innovative tool for combating the high rates of resistance of pathogen, which is the common problem [6]. Torres-Sangiao et al. noted that the development of both alternative therapeutic and prophylaxis approaches based on nanotechnology was useful and could help early detection of infectious diseases. The applied nanodiagnosis can help achieve successful treatment, and the newly developed applications based on nanotechnology can provide a diagnostic system with an increased sensibility and efficiency of the diagnosis of infectious disease [6]. The nanodiagnosis can be useful for both classic and newly emerging infections (Table 1). For classical infectious diseases, the updated new generation of the diagnostic tool by nanotechnology is possible. For the newly emerging infectious disease, applied nanotechnology is useful for the development of the new diagnostic system. This is applicable for any new emerging infectious diseases, including to COVID-19.

Table 1. Advantages of applied nanodiagnosis for diagnosing infectious diseases.

\begin{tabular}{l|l} 
Group & Details \\
\hline $\begin{array}{l}\text { Classical } \\
\text { infection }\end{array}$ & $\begin{array}{l}\text { Improvement of the efficacy of the classical } \\
\text { diagnostic tool }\end{array}$ \\
\hline & Reducing the cost for diagnosis \\
\hline & $\begin{array}{l}\text { Increased sensitivity } \\
\text { Shortening turnaround time }\end{array}$ \\
$\begin{array}{l}\text { New emerging } \\
\text { infection }\end{array}$ & $\begin{array}{l}\text { Help early diagnosis } \\
\text { Lowering the cost for macroscale production } \\
\text { to combating pandemic }\end{array}$ \\
\hline & Short turnaround time for diagnosis \\
\hline &
\end{tabular}

The development of a new diagnostic tool for diagnosing the infectious disease is usually based on the classical diagnostic tool. The nanomaterial is applied for modification of the standard system to achieve the new nanodiagnostic tool. With advanced nanotechnologies such as the fabrication of nanomaterial, the new nanodiagnostic tool can be successfully developed.

\section{Applied nanodiagnosis for COVID-19}

COVID-19 is a newly emerging viral infection caused by a novel coronavirus, SARS CoV-2. As a new disease, it usually lacks knowledge and diagnostic/therapeutic tools. In the early stage, the medical scientist focuses the studies on the nature of the pathogen. When there is detail on the pathogen, the development of the new diagnostic system and the therapeutic alternative is done. Regarding the diagnostic system for COVID-19, the standard technique is the molecular diagnostic approach for the identification of the molecular component of the pathogenic virus [7,8]. The nanotechnology can also be applied for creating the new nanodiagnostic system for COVID-19 [9].

There are some new reports on nanodiagnosis for COVID-19. The important reports are summarized and present in Table 2.

As a new emerging infection, there are few reports on applied nanodiagnosis for diagnosing COVID-19. Many kinds of nanomaterials are already used for the development of diagnostic tools. The main aim of using a nanomaterial-based diagnostic tool is to increase the efficacy of the diagnostic test [14]. The easy-to-use point of care testing (POCT) might be 
developed based on the novel nanotechnology [15]. With POCT, the field diagnosis might be easier than the present requirement for testing at the medical center. Additionally, the naked eye diagnostic system might be developed based on novel nanotechnology. A good example is the new naked-eye nanodiagnosis system for the detection of COVID-19 using N gene-targeted antisense oligonucleotide capped plasmonic nanoparticles [16].

Table 2. Some new reports on nanodiagnosis for COVID-19.

\begin{tabular}{|c|c|}
\hline Authors & Details \\
\hline $\begin{array}{l}\text { Mertens et al. } \\
{[10]}\end{array}$ & $\begin{array}{l}\text { Mertens et al. reported on the development of a new COVID- } \\
19 \text { Ag Respi-Strip Diagnostic Assay }\end{array}$ \\
\hline Wen et al. [11] & $\begin{array}{l}\text { Wen et al. reported on the development of a new lateral flow } \\
\text { immunoassay strip for rapid detection of IgG antibody } \\
\text { against the SARS-CoV-2 virus [11]. }\end{array}$ \\
\hline Qiu et al. [12] & $\begin{array}{l}\text { Qiu et al. reported on the development of dual-functional } \\
\text { plasmonic photothermal biosensors for COVID-19 diagnosis } \\
\text { [12]. }\end{array}$ \\
\hline Huang et al. [13] & $\begin{array}{l}\text { Huang et al. reported on the development of a new rapid } \\
\text { detection of IgM antibodies against the SARS-CoV-2 virus } \\
\text { [13]. This new nanodiagnosis tool is based on a newly } \\
\text { developed colloidal gold nanoparticle-based lateral-flow } \\
\text { assay [13]. }\end{array}$ \\
\hline
\end{tabular}

The frequently used nanomaterial is gold nanoparticles, which might be in various forms (such as colloidal gold nanoparticle and gold nanoislands [10, 11]). The other nanomaterials that are reported for their applications include Superparamagnetic nanoparticles [17] and Lanthanide-Doped Nanoparticles [18]. Regarding silver nanoparticles, the application is usually focused on the possible antiviral properties [19 - 21]. It is no doubt that applied nanotechnology for managing the emerging COVID-19 is the present hope for successful containment of the crisis [22]. Many attempts lead to success in developing of new nanodiagnosis tool for COVID-19 diagnosis. Nevertheless, the available reports usually show that the nanodiagnostic tool is helpful for diagnostic purposes. It is necessary to promote nanomedicine research regarding COVID-19.

\section{Conclusions}

The applied nanotechnology for the development of a new drug is a well-known application in nanomedicine [23]. Nanotechnology is also applicable to the development of new nanodiagnosis for COVID-19. The new nanomaterial-based diagnosis for COVID-19 is already developed and becomes a useful tool for containing the present COVID-19 outbreak crisis.

\section{Funding}

This research received no external funding.

\section{Acknowledgments}

This research has no acknowledgment.

\section{Conflicts of Interest}

The authors declare no conflict of interest. 


\section{References}

1. Pascarella, G.1 Strumia, A.; Piliego, C.; Bruno, F.; Del Buono, R.; Costa, F.; Scarlata, S.; Agrò, F.E. COVID19 diagnosis and management: a comprehensive review. J Intern Med 2020, 288, 192-206, https://doi.org/10.1111/joim.13091.

2. Garrido, I.; Liberal, R.; Macedo, G. Review article: COVID-19 and liver disease-what we know on 1st May 2020. Aliment Pharmacol Ther 2020, 52, 267-275, https://doi.org/10.1111/apt.15813.

3. Jan, H.; Faisal, S.; Khan, A.; Khan, S.; Usman, H.; Liaqat, R.; Shah, S.A. COVID-19: Review of Epidemiology and Potential Treatments Against 2019 Novel Coronavirus. Discoveries (Craiova) 2020 , 26, e108, https://doi.org/10.15190/d.2020.5.

4. Kavoosi, F.; Modaresi, F.; Sanaei, M.; Rezaei, Z. Medical and dental applications of nanomedicines. APMIS 2018, 126, 795-803, https://doi.org/10.1111/apm.12890.

5. Haddad, M.; Popovtzer, R.; Yariv, I.; Motiei, M.; Fixler, D. Concise Nanomedicine Review. Harefuah 2018, 157, 232-236.

6. Torres-Sangiao, E.; Holban, A.M.; Gestal, M.C. Advanced Nanobiomaterials: Vaccines, Diagnosis and Treatment of Infectious Diseases. Molecules 2016, 21, https://doi.org/10.3390/molecules21070867.

7. Li, X.; Geng, M.; Peng, Y.; Meng, L.; Lu, S. Molecular immune pathogenesis and diagnosis of COVID-19. J Pharm Anal 2020, 10, 102-108, https://doi.org/10.1016/j.jpha.2020.03.001.

8. Tang, Y.W.; Schmitz, J.E.; Persing, D.H.; Stratton, C.W. Laboratory Diagnosis of COVID-19: Current Issues and Challenges. J Clin Microbiol 2020, 58, e00512-20, https://doi.org/10.1128/JCM.00512-20.

9. Abd Ellah, N.H.; Gad, S.F.; Muhammad, K.E.; Batiha, G.; Hetta, H.F. Nanomedicine as a promising approach for diagnosis, treatment and prophylaxis against COVID-19. Nanomedicine (Lond) 2020, 20200247, https://doi.org/10.2217/nnm-2020-0247.

10. Mertens, P.; De Vos, N.; Martiny, D.; Jassoy, C.; Mirazimi, A.; Cuypers, L.; Van den Wijngaert, S.; Monteil, V.; Melin, P.; Stoffels, K.; Yin, N.; Mileto, D.; Delaunoy, S.; Magein, H.; Lagrou, K.; Bouzet J, Serrano, G.; Wautier, M.; Leclipteux, T.; Van Ranst, M.; Vandenberg O.; LHUB-ULB SARS-CoV-2 Working Diagnostic Group. Development and Potential Usefulness of the COVID-19 Ag Respi-Strip Diagnostic Assay in a Pandemic Context. Front Med (Lausanne) 2020, 7, https://doi.org/10.3389/fmed.2020.00225.

11. Wen, T.; Huang, C.; Shi, F.J.; Zeng, X.Y.; Lu, T.; Ding, S.N.; Jiao, Y.J. Development of a lateral flow immunoassay strip for rapid detection of IgG antibody against SARS-CoV-2 virus. Analyst 2020, 145, 53455352, https://doi.org/10.1039/d0an00629g.

12. Qiu, G.; Gai, Z.; Tao, Y.; Schmit, J.; Kullak-Ublick, G.A.; Wang, J. Dual-Functional Plasmonic Photothermal Biosensors for Highly Accurate Severe Acute Respiratory Syndrome Coronavirus 2 Detection. ACS Nano 2020, 14, 5268-5277, https://doi.org/10.1021/acsnano.0c02439.

13. Huang, C.; Wen, T.; Shi, F.J.; Zeng, X.Y.; Jiao, Y.J. Rapid Detection of IgM Antibodies against the SARSCoV-2 Virus via Colloidal Gold Nanoparticle-Based Lateral-Flow Assay. ACS Omega 2020, 5, 1255012556, https://doi.org/10.1021/acsomega.0c01554.

14. Rabiee, N.; Bagherzadeh, M.; Ghasemi, A.; Zare, H.; Ahmadi, S.; Fatahi, Y.; Dinarvand, R.; Rabiee, M.; Ramakrishna, S.; Shokouhimehr, M.; Varma, R.S. Point-of-Use Rapid Detection of SARS-CoV-2: Nanotechnology-Enabled Solutions for the COVID-19 Pandemic. International Journal of Molecular Sciences 2020, 21, E5126, https://doi.org/10.3390/ijms21145126.

15. Nikaeen, G.; Abbaszadeh, S.; Yousefinejad, S. Application of nanomaterials in treatment, anti-infection and detection of coronaviruses. Nanomedicine (Lond) 2020, 15, 1501-1512, https://doi.org/10.2217/nnm-20200117.

16. Moitra, P.; Alafeef, M.; Dighe, K.; Frieman, M.B.; Pan, D. Selective Naked-Eye Detection of SARS-CoV2 Mediated by N Gene Targeted Antisense Oligonucleotide Capped Plasmonic Nanoparticles. ACS Nano 2020, 14, 7617-7627, https://doi.org/10.1021/acsnano.0c03822.

17. Szunerits, S.; Nait Saada, T.; Meziane, D.; Boukherroub, R. Magneto-Optical Nanostructures for Viral Sensing. Nanomaterials (Basel) 2020, 10, E1271, https://doi.org/10.3390/nano10071271.

18. Chen, Z.; Zhang, Z.; Zhai, X.; Li, Y.; Lin, L.; Zhao, H.; Bian, L.; Li, P.; Yu, L.; Wu, Y.; Lin, G. Rapid and Sensitive Detection of anti-SARS-CoV-2 IgG, Using Lanthanide-Doped Nanoparticles-Based Lateral Flow Immunoassay. Anal Chem 2020, 92, 7226-7231, https://doi.org/10.1021/acs.analchem.0c00784.

19. Sportelli, M.C.; Izzi, M.; Kukushkina, E.A,; Hossain, S.I.; Picca, R.A.; Ditaranto, N.; Cioffi, N. Can Nanotechnology and Materials Science Help the Fight against SARS-CoV-2? Nanomaterials (Basel) 2020 , 10, 802, https://doi: 10.3390/nano10040802.

20. Sivasankarapillai, V.S.; Pillai, A.M.; Rahdar, A.; Sobha, A.P.; Das, S.S,; Mitropoulos, A.C.; Mokarrar , M.H.; Kyzas, G.Z. On Facing the SARS-CoV-2 (COVID-19) with Combination of Nanomaterials and Medicine: Possible Strategies and First Challenges.Nanomaterials (Basel) 2020, 10, E852, https:// doi: 10.3390/nano10050852.

21. Nasrollahzadeh, M.; Sajjadi, M.; Soufi, G.J..; Iravani, S.; Varma, R.S. Nanomaterials and NanotechnologyAssociated Innovations against Viral Infections with a Focus on Coronaviruses. Nanomaterials (Basel) 2020 , 10, 1072, https:// doi: 10.3390/nano10061072. 
22. Know the unknown fact of novel COVID -19 corona virus. Lett Appl NanoBioSci 2020. 9, 1083-1088, https:// doi.org/10.33263/LIANBS92.10831088.

23. Potential advancements of nanocarriers in topical drug delivery: a mini review. Lett Appl NanoBioSci 2020. 9, 968-974, https:// doi.org/10.33263/LIANBS92.968974. 